Research Article

J Exp Clin Med

2021; 38(4): 613-621

doi: 10.52142 /omujecm.38.4.39

\title{
Information and behaviors of patients applying to chest diseases outpatient clinic regarding rational use of drugs
}

\author{
Duygu ZORLU ${ }^{1 *}$ (i), Gülhan ÜNLÜ ${ }^{2}$ (i) \\ ${ }^{1}$ Department of Pulmonology, Faculty of Medicine, Ahi Evran University, Kırşehir, Turkey \\ Department of Pharmacology, Faculty of Medicine, Ahi Evran University, Kırşehir, Turkey
}

\begin{abstract}
Received: 23.02 .2021
Accepted/Published Online: 14.03.2021

-

Final Version: 30.08.2021

Abstract

Rational Drug Use (RUD), which aims to use drugs, when necessary, in the appropriate amount and in an appropriate way, is required from the physician with the rational choice of drugs and prescribing; health policies cover a process that includes other individuals in the society, pharmacists, healthcare professionals and consists of many steps, from the conscious and correct consumption of drugs to the patient. In determining RUD, it is important to reveal the knowledge and behavioral characteristics of individuals at these stages. Irrational drug use is one of the major health problems in developing countries, including our country. In our study, it was aimed to evaluate the patient parameter in RUD. For this purpose, it was tried to determine the knowledge and behaviors of the patients who applied to Chest Diseases outpatient clinic for any reason. This descriptive study was carried out with 163 volunteers who applied to the 3rd Stage Health Institution Chest Diseases Policlinic due to any respiratory symptoms. The data were obtained by face-to-face descriptive questionnaire. The questionnaire consisted of 16 questions about the sociodemographic characteristics of the patients and their knowledge and behavior regarding drug use. The response rates and compliance with the RUD were evaluated. According to the analysis results, most of the patients were between the ages of 51-64 and primary school graduates $(n=71,43.6 \%)$. The number of female patients was $80(49.1 \%)$ and the number of male patients was 83 (50.9\%), and the distribution of patients was found to be similar in terms of gender. $33.1 \%$ of the patients prescribed medication and kept them at home without being sick, thinking that it might be necessary, and most of these drugs were pain relievers $(29.4 \%)$. Only $10.4 \%$ were taking medication or demanding a prescription from their doctor with the advice of their neighbors and / or relatives. $11.1 \%$ of them used antibiotics on their own, without being examined due to complaints such as flu, cold, and cold. In our study, the characteristics of knowledge and behavior in accordance with RUD were determined to the patient who applied to the chest diseases outpatient clinic. Rational drug use is very important in terms of preventing unnecessary national expense, side effects, adverse effects, and decreasing mortality and morbidity. In order to raise the awareness of individuals on drug use in the society; Health policy, healthcare professionals, media and educators have important responsibilities.
\end{abstract}

Kevwords: rational drug use, medicine, chest diseases outpatient clinic, patients

\section{Introduction}

According to the definition of the World Health Organization (WHO), a medicine is "a substance or product that is used or intended to be used to change or examine physiological systems or pathological conditions for the benefit of the user" (1). Following the great progress that occurred with the discovery of Acetyl Salicylic Acid in the $20^{\text {th }}$ century, many medicines were produced and medicines were discovered for the treatment of many diseases until the 1970s (2).

Prescribing more medicines than necessary, irrational medicine use, where there are problems such as incorrect or excessive use of medicines, is one of the important health problems in developing countries including our country (3). Irrational use of medicines increases the morbidity and mortality rates by causing the medicines not to reach the required places and not taking the required doses. Besides, the development of resistance mechanisms is an important result in inappropriate use (4). Also, irrational medicine use leads to failure to benefit from treatment, an increase in the side effects and incidence of complications $(5,6)$. The rapidly increasing number of medicines, the use of over-the-counter medicines on own in minor health problems and the rapid proliferation of over-the-counter medicines reveal the necessity of taking precautions for rational use of medicines (7).

WHO defined Rational Use of Medicine as "A set of rules that must be followed in order for patients to take medicines in accordance with their clinical needs, in doses to meet their personal needs, in sufficient time, at the lowest cost to themselves and the community" at the meeting in Nairobi in 
1985. And created the List of Essential Medicines in 1977 (8). The rational use of medicines, which aims to use medicines when necessary, in appropriate amounts and appropriately, includes a process consisting of many steps from the physician to health policies, other individuals in the society, pharmacists, healthcare professionals, and to the patient with the conscious and correct consumption of medicines to patient with rational medicine selection and prescribing (6).

In Turkey, the Rational Use of Medicine Branch Directorate was established in 2010 under the roof of the Ministry of Health, General Directorate of Pharmaceuticals and Pharmacy. Yet, for the regulations of Rational Use of Medicines, "Turkish Medicines and Medical Devices Agency" was established in November 2011. "A European Union Lifelong Learning Program Project for rational Use of Medicines education with distance education method has been realized and pilot studies have been completed by Refik Saydam Hygiene Center Presidency School of Public Health Directorate. Although Turkey does not have a list of essential medicines, recommendations have been made for the preparation of the "National List of Medicines" and "National Medicine Formulas" but have not yet been implemented $(5,9)$.

The "Turkish Medicine Guide" was first issued by Prof. Dr. S. Oğuz Kayaalp in 1999 after being adapted from the British National Formulas and was continuously updated and the 6th edition was published in 2011. Diagnosis and treatment guidelines were prepared by the Ministry of Health, but could not be updated continuously. In conclusion, we have serious deficiencies in terms of medicines and treatment with medicines (5).

In order to ensure rational use of medicines, it is important to determine the medicine use knowledge and behavior attitude of the society. In our study, it was aimed to evaluate the role of patients in RUM (Rational Use of Medicines). For this purpose, it was tried to determine the knowledge and behaviors of the patients who applied to Chest Diseases outpatient clinic for RUM

\section{Materials and methods}

Ethics Committee Approval for the study was obtained from the Ahi Evran University Faculty of Medicine Clinical Research Ethics Committee with the decision No 2020-02/23, Date 11.02.2020. Written consent was obtained from each volunteer participant.

\subsection{Study population}

The descriptive study was conducted on 163 random volunteers who admitted to the Chest Diseases Polyclinic in February 2020 due to any respiratory complaint. After obtaining verbal and written consent from the volunteers participating in the study, a questionnaire was administered by the researchers, without asking their personal identity information, by face-to-face interviews (Table 1).

The questionnaire form consists of four questions that question age, gender, education level and descriptive features of chronic diseases and twelve closed-ended questions that question the attitude towards medicine use. The questions were prepared according to the "Rational Use of Medicines Guide" (6).

Questions questioning the knowledge and behavioral characteristics of medicine use are what they did after any treatment, where they kept the medicines without any warnings about the storage conditions, whether they prescribed medicines without being sick with the thought that it might be necessary, and which group of these medicines are, whether they use medicine with the recommendation of their neighbors and/or relatives or whether they want to prescribe them to their doctor, what they do when they are sick, whether they recommend medicine to the acquaintances with similar complaints, how they use the medicine that physician prescribed, whether they used antibiotics on own without being examined on complaints such as flu, cold, and influenza, where they learned about the use of the medicine and its possible side effects, how they behave if they encounter the side effects of the medicine, whether they bought the medicine from the pharmacy without a doctor's examination.

Answers were recorded for each patient, and response rates were associated with the descriptive characteristics of the patients and their knowledge and behavior about medicine use.

\subsection{Statistical analysis}

Categorical variables were shown as frequency (n) and percentage (\%) in the analysis of the data. Chi-Square test was used for group comparisons of categorical variables. $p<0.05$ was considered statistically significant. All analyzes performed with SPSS v.21 (IBM Corp. Released 2012. IBM SPSS Statistics for Windows, Version 21.0. Armonk, NY: IBM Corp.).

\section{Results}

$80(49.1 \%)$ of 163 patients were female, $83(50.9 \%)$ were male. Most of the female and male patients were between the ages of 51-64 $(\mathrm{n}=22,44 \% ; \mathrm{n}=28,56 \%$, respectively). The education level of the majority of the patients was at the primary school level of $28(56 \%)$ (Table 2).

In addition, 57 (35\%) of the patients had Asthma/COPD (Chronic Obstructive Pulmonary Disease), 38 (23.3\%) had hypertension, $24(14.7 \%)$ had diabetes mellitus (DM), 32 $(19.6 \%)$ were among the patients with other chronic diseases (such as Rheumatoid arthritis, Chronic Renal Failure, Chronic Liver Disease) and 54 (33.1\%) of them did not have any chronic diseases (Table 3 ). 
Table 1. Descriptive face-to-face questionnaire form

Date: .../.../....

City/District where you live:

1. Your age?

$18-30$

$31-40$

41-50

$51-64$

65 and older

2. Your gender?

$$
\text { Female Male }
$$

3. Your educational status?

Illiterate

Primary school

High school

Higher education

Master/PhD

4. Do you have any chronic diseases?

Asthma/COPD

Diabetes

Hypertension

Other

5. What do you do with the remaining medicine after any treatment?

I keep it for use when necessary.

I give it to a health institution.

I give it to a pharmacy.

I give it to the relatives who want it.

I throw it in the bin.

I flush it in the toilet.

Other

6. Where do you store medicines for which there are no warnings about storage conditions?

In refrigerator

In the freezer/deep freezer

At room temperature in a cool and dry place

7. Do you request to get a prescription or buy medicine and keep it at home without getting sick, thinking it might be necessary? Yes $\quad$ No (Please procedd to the question 9)

8. Which group of medicines are these?

Pain killers

Antibiotics

Cold medicines

Vitamins

Stomach medicines

Eye drops

Nasal sprays

Allergy medicines

Ointments

All

Other

9. Do you take medicine with the advice of your neighbors and/or relatives or would you like your doctor to prescribe it? Yes No

10. What do you do when you get sick?

I consult the doctor.

I consult the pharmacist.

I consult with a nurse, health official or healthcare professional.

I consult with my acquaintance/neighbor/relative.

I try herbal remedies.

I try to be treated with medicines available at home.

I ask those who have had a similar condition to mine before.

Other (Please specify.). 
11. Do you recommend medicine to your acquaintances with similar complaints? Yes No

12. How do you use the medicines prescribed by your physician?

I use it until the medicine is over.

I use it until my complaint passes.

I use it as long as the doctor or pharmacist recommends.

Other (Please specify.).

13. Do you use antibiotics on your own without being examined for your complaints such as flu, cold, and influenza?

Yes, I do.

Yes, I start but stop using the medicine when I feel well.

No; I do not use it without examination.

14. Where can you find information about the use of the medicine and its possible side effects?

Pharmacist

Assistant health personnel (nurse, midwife, health officer, etc.)

Package leaflet of the medicine

Internet

Doctor

15. How would you behave if you experience side effects due to the medicine?

I consult the doctor.

I consult the pharmacist.

I apply to assistant health personnel (nurse, midwife, health officer, etc.).

I look for a solution myself.

I do nothing.

16. Do you buy medicine from the pharmacy without being examined by a doctor?

Yes; when I don't want to pay for money for the examination visit

No; I don't take medicine without being examined, a serious disease may be missed.

There was no statistically significant difference between age groups and genders $(\mathrm{p}=0.512)$. However, there is a significant relationship between age groups and education level; while the illiteracy rate was higher in group of 65 years and above, the percentage of higher education graduates was found to be higher among those aged 18-30 ( $<<0.001)$ (Table 4).

Table 2. Age distribution rates of patients in their own gender groups

\begin{tabular}{|l|l|l|l|l|}
\hline & Gender & $\begin{array}{l}\text { Chi- } \\
\text { Square } \\
\text { value }\end{array}$ & p-value \\
\hline $\begin{array}{l}\text { Age } \\
\text { Groups }\end{array}$ & $\begin{array}{l}\text { Female } \\
(\mathbf{n = 8 0 , 4 9 . 1 \% )}\end{array}$ & $\begin{array}{l}\text { Male } \\
(\mathbf{n}=\mathbf{8 3}, \mathbf{5 0 . 9} \%)\end{array}$ & & \\
\hline $\mathbf{1 8 - 3 0}$ & $16(53.3)$ & $14(46.7)$ & & \\
$\mathbf{3 1 - 4 0}$ & $16(57.1)$ & $12(42.9)$ & & \\
\hline $\mathbf{4 1 - 5 0}$ & $18(54.5)$ & $15(45.5)$ & 3.28 & 0.512 \\
\hline $\begin{array}{l}\mathbf{5 1 - 6 4} \\
\mathbf{6 5} \text { and } \\
\text { older }\end{array}$ & $82(44)$ & $28(56)$ & & \\
\hline
\end{tabular}

Table 3. Chronic disease distribution characteristics of the patients

\begin{tabular}{|l|l|l|}
\hline Asthma/COPD & $\mathbf{5 7}$ & $\mathbf{3 5}$ \\
\hline Diabetes & 24 & 14.7 \\
\hline Hypertension & 38 & 23.3 \\
\hline Other & 32 & 19.6 \\
\hline Have no chronic disease & 54 & 33.1 \\
\hline
\end{tabular}

The answers to the questions evaluating the medicine use knowledge and behavioral characteristics of the patients were as follows (Table 5): "What do you do with the remaining medicine after any treatment?": $39 \%(n=64)$ said they would keep them for use when necessary, $26.2 \%(n=43)$ said they will give it to the health institution, $12.2 \%$ of them stated that they threw them away. "Do you request to get a prescription or buy medicine and keep it at home without getting sick, thinking it might be necessary": $33.1 \%$ of the patients $(n=54)$ answered yes, and the medicines they mostly have at home were $29.4 \%$ $(n=48)$ pain medicines, the least available were stomach medicines, and eye drops $1.2 \%(\mathrm{n}=2)$. "Do you use antibiotics on your own without being examined for your complaints such as flu, cold, and influenza": $89.6 \%(n=146)$ of the patients answered "No". "What do you do when you get sick:" $92 \%$ $(n=150)$ of the patients stated that they went to the doctor, $1.8 \%$ $(\mathrm{n}=3)$ consulted the pharmacist and healthcare personnel, and $4.9 \%(n=8)$ tried herbal treatment methods. "'How do you use the medicines prescribed by your physician": $54.9 \%(n=89)$ of the patients stated that they used the medicine for the time recommended by the doctor/pharmacist, $31.3 \%(n=51)$ stated that until the medicine is finished, and $14.1 \%(n=23)$ stated that they use it until the complaint recovers. "Do you use antibiotics on your own without being examined for your complaints such as flu, cold, and influenza?": $89 \%$ of the patients $(n=145)$ stated that they did not use medicine without being examined. "Do you buy medicine from the pharmacy without being examined by a doctor'": $94.5 \%(n=154)$ of the 
patients answered "No".

Table 4. Distribution characteristics of the patients by age group and education level

\begin{tabular}{|c|c|c|c|c|c|}
\hline $\begin{array}{c}\text { Age } \\
\text { Groups }\end{array}$ & Literate & $\begin{array}{c}\text { Primary } \\
\text { school }\end{array}$ & $\begin{array}{c}\text { High } \\
\text { school }\end{array}$ & $\begin{array}{c}\text { Higher } \\
\text { education }\end{array}$ & $\begin{array}{l}\text { Master/ } \\
\text { PhD }\end{array}$ \\
\hline $18-30$ & $0(0)$ & $4(13.3)$ & $9(30)$ & $14(46.7)$ & $3(10)$ \\
\hline $31-40$ & $1(3.6)$ & $8(28.6)$ & $\begin{array}{c}12 \\
(42.9)\end{array}$ & $5(17.9)$ & $2(7.1)$ \\
\hline $41-50$ & $0(0)$ & $18(54.5)$ & $\begin{array}{c}10 \\
(30.30\end{array}$ & $4(12.1)$ & $1(3)$ \\
\hline $51-64$ & $2(4)$ & $28(56)$ & $\begin{array}{c}13 \\
(26)\end{array}$ & $6(12)$ & $1(2)$ \\
\hline $\begin{array}{c}65 \text { and } \\
\text { older }\end{array}$ & $5(22.7)$ & $13(59.1)$ & $1(4.5)$ & $2(9.10)$ & $1(4.5)$ \\
\hline
\end{tabular}

\section{Discussion}

Many factors are important in providing RUM. These factors can be classified as non-sick individuals, physicians, patients, nurses and other assistant health personnel, manufacturer company, pharmacy and health policy $(10,11,12)$. In our study, the role of patients in RUM was tried to be evaluated.

People are expected to admit to the physician for the diagnosis and treatment of these diseases when they got sick. However, it can be seen that this behavior is not always exhibited (13). With a satisfactory result in our study, 92\% of the participants stated that they went to the doctor when they got sick. In a study conducted on this subject, $75.7 \%$ of the participants answered the question "what do you do first when you get sick" that "I would go to the doctor", 15.0\% answered that "I would use the medicines available at home", and 4.7\% that "I would do nothing" $(14,15)$. The rate of answers given to this question was found to be high in our study; however, there are a few studies consistent with our result (16). The fact that this percentage was higher in our study may be due to the fact that patients were evaluated in a tertiary health institution, a specific outpatient clinic and patients with follow-up due to chronic diseases, and therefore, more conscious and continuous communication with the physician. It also suggests that the prohibition of over-the-counter medicine purchase by the Ministry of Health is effective in increasing this rate. Because, since the study mentioned above was conducted in 2011, that is, before the creation of the RUM National Action Plan, the rate may have been found lower than in our study. Studies on the RUM in the Ministry of Health is continuing for nearly 20 years, and RUM Unit was established in 2010, and
RUM, Medicine Supply Management and Promotion Department was established within the Turkish Pharmaceuticals and Medical Devices Agency in 2012. In order to ensure coordination, RUM Provincial Representative was determined in Provincial Health Directorates in 81 provinces, and the RUM National Action Plan (2014-2017) was established. By all outward appearances, studies on RUM in specific branches and diseases are also rare (17).

In our study, most of the patients stated that they did not take medicine without medical examination, but it was observed that the rate of using the medicines prescribed by the physician during the period recommended by the physician decreased. In a study conducted on this issue, $77.3 \%$ of individuals used medicine without a physician's recommendation, $26.2 \%$ increased/decreased their medicine without consulting a physician, $84.4 \%$ followed the prescribed medicine hours, $77.3 \%$ of them stated that they stopped using medicine before the period recommended by the physician. In this study, the most important problem was that individuals had health behaviors that need to be developed in terms of RUM, and especially the use of medicines without consulting a doctor and discontinuing the medicine before the recommended time (16).

The rate of participants who got a prescription and purchased medicines without getting sick considering that it might be necessary was low in our study. The medicines that are most commonly available at home without getting sick are painkillers, cold medicines, antibiotics and vitamins, respectively. In a study conducted on this subject, it was stated that $31.3 \%$ of the participants bought medicines without a prescription from the pharmacy. Similar to our study results, the most common over-the-counter medicine was pain relievers (90.4\%) (14). The higher percentage of admitting to doctors in our study may be due to the fact that the study was carried out in a tertiary health institution and the Ministry of Health prohibited taking medicines without a prescription.

The vast majority of the patient population in our study stated that they did not use any medicine with the advice of their neighbors and/or relatives and did not use antibiotics on their own for flu, cold, and influenza complaints, and they were examined by a physician. According to a study conducted, these rates on RUM were higher (15).

Table 5. Answer rates of the patients to the questions

\section{What do they do with the remaining medicine after any treatment}

I keep it for use when necessary.

I give it to a health institution.

I give it to a pharmacy.

I give it to the relatives who want it.

\begin{tabular}{|c|c|}
\hline $\mathbf{n}$ & $\mathbf{\%}$ \\
\hline 64 & 39.0 \\
\hline 43 & 26.2 \\
\hline 17 & 10.4 \\
\hline 3 & 1.8 \\
\hline
\end{tabular}


I throw it in the bin

20

I flush it in the toilet.

Other

Request to get a prescription or buying medicine and keeping at home without getting sick, thinking it might be necessary

Yes

Which group of medicines are the medicines they keep at home

Pain killers

Antibiotics

Cold medicines

Vitamins

Stomach medicines

Eye drops

Nasal sprays

Allergy medicines

Ointments

All

Whether they used medicine with the recommendation of their neighbors and/or relatives or whether they asked their doctor to prescribe

Yes

No

What they do when they get sick

I consult the doctor.

I consult the pharmacist.

I consult with a nurse, health official or healthcare professional.

I consult with acquaintances/neighbors/relatives

I try herbal remedies.

I try to be treated with medicines available at home.

I ask those who have had a similar condition to mine before.

Other

Whether or not recommending medicine to acquaintances with similar complaints

Yes

No

How do they use the medicines prescribed by the physician

I use it until the medicine is over.

I use it until my complaint passes.

I use it as long as the doctor and pharmacist recommends.

Cases of using antibiotics on their own without being examined due to complaints such as flu, cold, and influenza 
Yes, I do.

Yes, I start but stop using the medicine when I feel well.

12

6

145

No; I do not use it without examination.

Where can they learn information about the use of the medicine and its possible side effects

Doctor

Pharmacist

Assistant health personnel

Package leaflet of the medicine

Internet

I do not learn

How they behave when faced with the side effects of the medicine

I consult the doctor.

I consult the pharmacist.

Assistant health personnel

I look for a solution myself.

I don't do anything

Whether or not to take medicine from the pharmacy without medical examination

Yes

No
26

3

91

11
7.4

3.7

89

29.4

16

1.8

55.8

6.7

0.6
1.8

3.7

1.8

5.5

94.5
When the patients were asked what they did the medicines after the treatment, the majority of the patients stated that they kept them for use when necessary or gave them to a healthcare institution. Unfortunately, a considerable number of patients also stated that they threw away the medicines. They stated that the majority of information about the use of medicines and possible side effects was obtained from the package insert and they applied to the physician when they experienced possible medicine side effects.

As can be seen from our results, the patient population we work with generally has information and behavioral characteristics suitable for RUM. We think that these results are effective because the patients were evaluated in a tertiary health institution and they had more frequent contact with physicians due to their chronic diseases. An important result is that pulmonologists are quite effective in patient knowledge and behavior in RUM in outpatient clinic practices.

One of the limitations of our study can be that we did not calculate the cost. Because, according to WHO data, the budget allocated for pharmaceutical expenditures in the whole world in 2006 is approximately 859 billion USD. The share allocated for pharmaceutical expenditures in the global gross product is $24.9 \%$ on average (3). According to 2009 data, medicine expenditures constitute $16 \%$ of per capita health expenditures in high income countries, $24 \%$ in middle income countries and $29 \%$ in low-income countries $(17,18)$. As the data supports, as the development level of countries increases, expenditure on pharmaceuticals decreases. According to the Turkish National Health Accounts Survey conducted in 1991-2000, the total expenditure of our country for medicines and non-durable medical consumables for 2000 was calculated as 2 Billion 763 Million TRY. Accordingly, the share of total medicine and medical consumable expenditure in total health expenditure is $33.5 \%$ (14). According to the data in the health expenditures research produced in accordance with the health accounts system of the Ministry of Health, General Directorate of Health Research (SAGEM), Organization for Economic Development and Cooperation (OECD), it was shown that the share of total health expenditure in the Gross Domestic Product (GDP), which was 4.9 billion in 1999, increased from $4.8 \%$ in 1999 to $5.9 \%$ in 2011 (7). In 2009, medicine expenditures constituted $45.7 \%$ of the total expenditures of the Social Security Institution and $24.7 \%$ of the total public health expenditures in Turkey $(19,20)$. Despite the measures of the SSI, the health and medicine expenditures in Turkey increased by $2.7 \%$ in 2011 and exceeded 15 billion TL (7). In Turkey where a total of 1 billion 700 million boxes of medicines are consumed, 
antibiotics are in the first place in consumption, while the amount paid for medicines is 1 Billion 253 Million TRY for antibiotics and 939 Million TRY for painkillers (7).

Although compliance with RUM is observed in our study, the population we work with represents a small cross-sectional sample of the society. Therefore, the knowledge and behavioral characteristics of RUM will be revealed more clearly with studies that evaluate other factors effective in wider patient populations and RUM separately.

Another limitation of our study is the lack of questioning about the use of specific medicines such as inhaler medicines. The reason for this is the thought that objective results cannot be obtained with a specific outpatient clinic evaluation and a more conscious patient profile with follow-up due to chronic diseases. Besides, the fact that RUM was not evaluated in terms of both patients and physicians in specific patient groups such as Asthma and COPD can be considered among the limitations of the study and this issue can be evaluated in different studies. Because RUM is evaluated under sub-headings such as RUM in the elderly, rational use of antibiotics, inhaler medicine, rational use of painkillers, and rational use of acetyl salic acid (6). The main topic, RUM, was evaluated in our study. Because, according to $\mathrm{WHO}$, more than $50 \%$ of medicines worldwide are prescribed improperly. Also, 50\% of the patients do not take their medicines properly. Despite the current unnecessary and excessive use of medicines, nearly one third of the world population cannot even provide access to essential medicines $(5,9)$. In a study evaluating the RUM physician parameter on this subject and evaluating Inappropriate Antibiotic use in COPD exacerbations, it was observed that most pulmonologists tend to prescribe antibiotics for COPD exacerbations according to the defined GOLD (Chest Diseases COPD diagnosis and treatment guideline) criteria. However, it has been found that some physicians prefer to prescribe antibiotics on their own regardless of the GOLD criteria (19-21). In another study in which the physician parameter in the RUM was evaluated, researcher assistant physicians working in the Faculty of Medicine Hospital were evaluated. In this study, it was observed that the RUM knowledge and attitudes of physicians had deficiencies and revealed the necessity of updating this subject within the scope of continuous medical education $(17,22)$.

Providing and disseminating RUM is very important in terms of both our unnecessary national medicine expenses and the prevention of unwanted medicine effects and side effects, mortality and morbidity. In this regard, individuals, patients, physicians, health policies, pharmacists and pharmaceutical companies approach and practices are effective in the society. Limiting the use of non-prescription antibiotics, restricting the use of some medicines without a related branch report, and limiting the medicines intake by calculating the usage dose according to the duration were useful practices (21-24).

It is important that patients, even non-sick individuals, be informed about this issue. Hence, we think that it will be beneficial to inform and remind every patient who is examined in outpatient clinics by family physicians in public health centers at regular intervals, and at least RUM brochures are given together with a prescription. These approaches should be supported by health policies in line with the data obtained from broader studies, and Turkish National List of Essential Medicines, National Medicine Formulas and Medicine Guidelines, which have not yet been determined for our country, should be prepared and implemented.

In conclusion, it is important to raise the awareness of individuals about medicine use in the society, to provide RUM, in terms of our national medicine expenditures, treatment and side effects. Health policies, healthcare professionals, non-sick individuals, patients, media and educators have important responsibilities in ensuring and disseminating RUM.

\section{Conflict of interest}

None to declare.

\section{Acknowledgments}

We would like to thank Buse Aydın, $3^{\text {th }}$ grade nursing student for her contribution to our study.

\section{References}

1. Oktay Ş, Kayaalp S. Prescription rules and rational drug use. Medical pharmacology in terms of rational treatment, twelfth edition, Pelikan Medical and Technical Bookstore Ltd. Şti. 2009.

2. Quick JD, Hogerzeil HV, Velasquez G, Rago L. Twenty-five years of essential medicines. Bull World Health Organ. 2002;80(11):913-4.

3. Organization, W.H. Promoting rational use of medicines: core components. Geneva: World Health Organization, 2002.

4. Çelik Y. The evaluation of the appropriateness of the level of Turkey's health spending and health spending analysis. Journal of Social security 2011; 1(1): 62-81.

5. Akıcı A., Aydin V., Mollahaliloglu S., Ozgulcu S., Alkan A. Evaluation of knowledge and attitudes of general practitioners on rational drug use. Sted 2002; 11(7): 253-257.

6. Available from:www.akilciilac.gov.tr

7. Yapıcı, G, Balıkçı S, Uğur Ö. Attitudes and behaviors of those applying to primary health care institutions about drug use. Dicle Medical Journal 2011; 38(4): 458-465.

8. Aydin B, Gelal A. Rational Drug Use: Promotion and the Role Of Medical Education. J DEU Med. 2012; 26(1): 57-63.

9. Oktay Ş. History of Rational Use. Turkiye Klinikleri J Pharmacol-Special Topics. 2015; 3(1): 11-18.

10. Gülmez SE. Rational Use of Medicines Implementations in the World. Compilation. Turkiye Klinikleri J Pharmacol-Special Topics. 2015; 3(1): 34-44.

11. Özer E, Özdemir L. Rational Use of Drugs in the Elderly and Responsibilities of the Nurse. Hacettepe University Journal of Nursing Faculty 2009; 16(2): 042-51.

12. Şendir M, Çelik Z, Güzel E, Büyükyılmaz F. Determination of rational drug use habits in individuals applying to family health centers. TAF Prev Med Bull. 2015; 14(1): 15-22.

13. İlhan MN, Aydemir Ö, Çakır M, Aycan S. Irrational drug use behaviors: Three district examples in Ankara. TJPH. 2014; 
12(3): 188-200.

14. Organization, W.H., The pursuit of responsible use of medicines: sharing and learning from country experiences. 2012 World Health Organization.

15. Holloway K, Van Dijk L. Rational use of medicines. Chapter in: The world medicines situation 2011, Geneva. World Health Organization 2011.

16. Ercan, T, Biçer, D. F. Consumers' Knowledge Levels and Assessment of Factors Affecting Their Behaviors: Sivas Province Case. BMIJ. 2019; 7(2): 998-1021.

17. Ouédraogo D-D, Zabsonré JW, Tiendrebeogo EZ, Kakpovi KG, Kaboré F, Drabo JY, et al. Prevalence and factors associated with self-medication in rheumatology in Sub-Saharan Africa. Eur J Rheumatol. 2015; 2: 52-6.

18. Lu Y, Hernandez P, Abegunde D. The world medicines situation 2011; 35-38.
19. Acar A, Yeğenoğlu. Pharmacoeconomics and hospital formularies from the window of rational drug use. J Fac Pharm. 2005; 34(3): 207-218.

20. Varol Y, Karakurt Z, Çırak AK, Doğan Şahin H, Kıraklı C, Kömürcüoğlu B. Inappropriate antibiotic use in COPD exacerbations. Turk Thorac J. 2020; 21(6): 397-403.

21. Demirci B, Çilengir Ayhan F, Abacıgil F. Attitudes of Pharmacy Workers on Rational Drug Therapy: A Cross Sectional Survey. Med Bull Haseki. 2019; 57: 339-344.

22. Türk S. Using medicine with care. Mustafa Kemal University Medical Journal 2018; 9(33): 33-41.

23. Kıroğlu O, Berktaş F, Şahan E, Karataş Y. Knowledge and awareness of research assistants about rational drug use. Cukurova Medical Journal 2018; 43(1)1: 164-171.

24. https://www.aifd.org.tr/akilci-ilac-kullanimi/ 